\title{
Switching treatments in COPD: implications for costs and treatment adherence
}

\author{
This article was published in the following Dove Press journal: \\ International Journal of COPD \\ 3 December 2015 \\ Number of times this article has been viewed
}

\author{
Fulvio Braido' \\ Federico Lavorini ${ }^{2}$ \\ Francesco Blasi ${ }^{3}$ \\ Ilaria Baiardini ${ }^{1}, *$ \\ Giorgio Walter Canonical,* \\ 'Respiratory and Allergy Diseases \\ Clinic, Department of Internal \\ Medicine, University of Genoa, \\ IRCCS AOU San Martino-IST, Genoa, \\ ${ }^{2}$ Department of Experimental and \\ Clinical Medicine, Careggi University \\ Hospital, Florence, ${ }^{3}$ Department of \\ Pathophysiology and Transplantation, \\ Università degli Studi di Milano, \\ IRCCS Fondazione Ca' Granda, \\ Ospedale Maggiore Policlinico, Milan, \\ Italy \\ *These authors contributed equally \\ to this work
}

Correspondence: Fulvio Braido Respiratory and Allergy Diseases Clinic, Department of Internal Medicine, University of Genoa, IRCCS AOU San Martino-IST, Largo R Benzi I0, 16132 Genoa, Italy

Tel +39010 5553524

Fax +39010 5553524

Email fulvio.braido@unige.it
Abstract: Inhaled therapy is key to the management of chronic obstructive pulmonary disease (COPD). New drugs and inhalers have recently been launched or will soon become available, and the expiry of patent protection covering several currently used inhaled bronchodilators and corticosteroids will be accompanied by the development of bioequivalent, generic inhaled drugs. Consequently, a broader availability of branded and generic compounds will increase prescription opportunities. Given the time course of COPD, patients are likely to switch drugs and inhalers in daily practice. Switching from one device to another, if not accompanied by appropriate training for the patient, can be associated with poor clinical outcomes and increased use of health care resources. In fact, while it seems reasonable to prescribe generic inhaled drugs to reduce costs, inadequate use of inhaler devices, which is often associated with a poor patientphysician or patient-pharmacist relationship, is one of the most common reasons for failure to achieve COPD treatment outcomes. Further research is needed to quantify, as in asthma, the impact of inappropriate switching of inhalers in patients with COPD and show the outcomes related to the effect of using the same device for delivering inhaled medications.

Keywords: inhaled therapy, long-acting antimuscarinic agents, long-acting $\beta_{2}$ agonists, inhaled corticosteroids, metered-dose inhalers, dry powder inhaler

\section{Introduction}

Inhaled therapy is key to the pharmacological management of patients with chronic obstructive pulmonary disease (COPD). ${ }^{1}$ Compared with oral or intravenous drugs, inhaled therapy quickly delivers the drug directly to the internal lumen of the airways, thus lowering the dosage required and minimizing the side effects. The currently available inhaled drugs provide symptom relief, improve health status, enhance exercise capacity, and reduce the frequency and severity of COPD exacerbations. ${ }^{1}$

When the inhalation is performed correctly, all inhalers are equally effective, albeit at different doses. ${ }^{2,3}$ However, not all marketed devices fulfill patients' needs in terms of reliability, portability, usability, ease of use, and dose tracking. In addition, appropriate positive reinforcement and feedbacks is not always available. ${ }^{4}$

Both experts' group recommendation ${ }^{1}$ and documents from an international scientific society ${ }^{5}$ emphasize the importance of close monitoring of inhalation technique and improving the efficiency of drug delivery. Although inhaled drug delivery is a painless and convenient choice, it presents some disadvantages. First, inadequate use of the inhaler is one of the most common reasons for failure to achieve COPD treatment outcomes. ${ }^{6}$ Incorrectly performed inhalation maneuvers can hinder drug delivery and potentially reduce efficacy. ${ }^{3}$ Second, since inhaling medication is less manageable than oral administration ${ }^{7}$ and transdermal approaches, ${ }^{8}$ adherence may be affected. Furthermore, delivery of drugs by an inhaler requires the doctor to explain specific 
techniques that must be monitored at subsequent visits. During treatment, patients may find it difficult to use the device, thus leading to underuse, misuse, or both. ${ }^{6}$ Improper use inevitably has consequences for both the patient's health and the health system. ${ }^{9-11}$

A report from the European Respiratory Society and the International Society for Aerosols in Medicine recommends that patients with stable disease should remain on their current inhaler rather than switching to a new one. ${ }^{5}$ In fact, switching devices could lead the patient to perform the inhalation technique incorrectly, owing to a lack of instruction and experience. The potential consequences include suboptimal drug administration, unsatisfactory adherence to treatment, and increased management costs.

\section{Switching treatment in COPD: research findings}

Data on switching of inhaled treatment in COPD and its effect on disease outcomes are lacking. In their analysis of the PHARMO database from 2002 to 2006, Penning-van Beest et $\mathrm{al}^{12}$ analyzed COPD patients starting treatment with long-acting antimuscarinic agents (LAMA), long-acting $\beta_{2}$ agonists (LABA), and the fixed dose combination (FDC) of LABA and inhaled corticosteroids (LABA-ICS FDC). The patients were included in the analysis only if they had been prescribed a long-acting drug within 6 months of their first prescription and had been followed for 3 years. In this trial, switching was defined as starting one of the other two long-acting inhaled drug classes after the last dispensing of the first drug. Switching from one inhaled device to another while maintaining the same drug was not investigated. A total of 7,548 patients were assessed. Persistent rates with initial monotherapy recorded at 1,2 , and 3 years were as follows: $25 \%, 14 \%$, and $8 \%$ for LAMA; $21 \%, 10 \%$, and $6 \%$ for LABA; and 27\%, 14\%, and $8 \%$ for LAMA-ICS FDC. Among patients who did not continue LAMA alone for at least 1 year, 13\% switched therapy and 15\% added new drugs (essentially LABA-ICS FDC, which was also the option patients switched to in $74 \%$ of cases). Of the patients who did not continue LABA, 9\% added therapy and 31\% switched drugs, mostly to LABA-ICS FDC. In patients who did not continue with LABA-ICS FDC, 11\% switched drugs. Of these, $60 \%$ switched to LAMA. The reasons for poor adherence to treatment or switching were not analyzed, but factors leading to switching and worthy of further investigation included poor efficacy, adverse events, dosing regimen, and device acceptability.

The preference and satisfaction, lung function and disease outcome ${ }^{13}$ of patients who switch from one device to another while maintaining the same drug has been explored ${ }^{14}$ but the impact of switching on cost and adherence remains unstudied.

Switching can lead to the use of multiple inhalers, and consequently a worsened adherence is expected. This association has been demonstrated even after controlling for proxy measures of COPD severity in patients on treatment with two or more long-acting inhaled drugs, namely, patients were $34 \%$ less likely to adhere to therapy and had a $40 \%$ higher treatment discontinuation rate than patients taking a single long-acting inhaled drug. ${ }^{15}$

\section{COPD drugs: present and future}

New drugs and inhalers for the treatment of COPD have recently been launched or are in the process of being launched in several European countries. Some pharmaceutical companies have invested directly or indirectly in research and development of new inhalers, including the following: Respimat ${ }^{\text {t }}$ Soft Mist ${ }^{\mathrm{TM}}$, which is the inhaler chosen by Boehringer Ingelheim (Ingelheim am Rhein, Germany) for administration of the LAMA tiotropium and the LABA olodaterol and their FDC; the ELLIPTA ${ }^{\circledast}$ dry powder inhaler (DPI), which is marketed by GlaxoSmithKline (Brentford, UK) for administration of the LAMA umeclidinium, the LABA vilanterol, the corticosteroid fluticasone furoate, and FDCs; Genuair ${ }^{\circledR}$, which was acquired by AstraZeneca (London, UK) for administration of the LAMA aclidinium alone or in an FDC with the LABA formoterol; Breezhaler ${ }^{\circledR}$, which is marketed by Novartis (Basel, Switzerland) for administration of the LABA indacaterol and the LAMA glycopyrronium alone or in an FDC; Nexthaler ${ }^{\circledR}$, which was developed by Chiesi (Parma, Italy) for administration of the ICS-LABA FDC of beclomethasone dipropionate/formoterol, and combination with glycopyrronium; Spiromax ${ }^{\circledR}$, which is produced by TEVA (Petah Tikva, Israel) for the administration of the ICSLABA FDC formoterol/budesonide, and salmeterol/fluticasone propionate; Forspiro ${ }^{\circledR}$, selected by Sandoz (Holzkirchen, Germany) for the administration of the salmeterol/fluticasone propionate.

The expiry of the patent covering established inhaled bronchodilators, corticosteroids, and their FDCs has contributed to or will promote the development of generic inhaled drugs that are bioequivalent to the original branded medications. ${ }^{16}$ While generic inhaled medications have the same chemical structure as branded ones, they are not always delivered using the same device, which is often protected by ongoing patents. The European Medical Agency guideline approves the generic version of an inhaler product based on in vitro assessment if the product meets established criteria, thus enabling 
interchangeability. ${ }^{17}$ When in vitro comparability is not proven, it is necessary to perform a lung deposition analysis, which is sometimes accompanied by pharmacodynamics and/or clinical testing. Unlike oral or injected drugs, the European Medical Agency does not consider inhaled drugs as generic agents, but as hybrids. ${ }^{17}$ The US Food and Drug Administration (FDA) defines inhaled drugs as "therapeutic and diagnostic products that combine drugs, devices, and/or biological products". ${ }^{18}$ Therefore, given that one device differs from another, development of a generic is very challenging. ${ }^{19}$ In fact, the FDA requires manufacturers to demonstrate delivery to the lungs, systemic exposure, and device equivalence of both generic and branded products. ${ }^{19}$ The aforementioned rules have discouraged applications for generics in the USA, although there are many older pressurized metered-dose inhalers on the market without patent or exclusivity protection.

\section{Switching possibilities: the Italian case history}

The Italian Drug Agency has approved 17 different agents or their FDCs for the treatment of COPD. ${ }^{20}$ The list comprises three short-acting $\beta_{2}$ agonists (salbutamol, terbutaline, fenoterol), four LABA (salmeterol, formoterol, indacaterol, olodaterol), three LAMAs (tiotropium, aclidinium, glycopyrronium), four FDCs containing a $\beta_{2}$ agonist and an ICS (salbutamol/beclomethasone, formoterol/budesonide, salmeterol/fluticasone propionate, vilanterol/fluticasone furoate), two fixed combinations of a short-acting $\beta_{2}$ agonist and a short-acting antimuscarinic antagonist (fenoterol/ipratropium bromide, salbutamol/ipratropium bromide), and one FDC of a LABA and a LAMA (indacaterol/glycopyrronium). The launch of the FDCs umeclidinium/vilanterol, formoterol/aclidinium, formoterol/ beclomethasone, salmeterol/fluticasone propionate, and olodaterol/tiotropium under different brand names is envisaged for the second semester of 2015 or the first semester of 2016.

Considering all drugs already approved by the Italian Drug Agency, 41 different brands are now available and a total of 13 different inhaled devices are now on the market. Matching compounds, devices, and types of manufacture enable physicians to prescribe a series of products (one drug or a combination of drugs) with 48 possible switches (Table 1).

Since several patented single drugs or drug combinations have expired or will soon expire, the advent of generic compounds will increase prescription opportunities. For example, formoterol is available in Italy under 12 brand names with 5 different inhalers, providing a total of 21

Table I Licensed and launched soon inhaled drugs for COPD treatment in Italy

\begin{tabular}{|c|c|c|c|}
\hline Drug & Formulation & Device & $\begin{array}{l}\text { Company (international headquarters } \\
\text { location) }\end{array}$ \\
\hline \multicolumn{4}{|l|}{ SABA } \\
\hline \multirow[t]{2}{*}{ Salbutamol } & Pressurized suspension & MDI & Sandoz (Holzkirchen, Germany) \\
\hline & Pressurized suspension & MDI & GlaxoSmithKline (Brentford, UK) \\
\hline Terbutaline & Multidose dry powder & Turbohaler & AstraZeneca (London, UK) \\
\hline Fenoterol & Pressurized solution & MDI & Boehringer Ingelheim (Ingelheim am Rhein, Germany) \\
\hline \multicolumn{4}{|l|}{ LABA } \\
\hline \multirow[t]{6}{*}{ Salmeterol } & Pressurized suspension & MDI & Dompè (Milan, Italy) \\
\hline & Multidose dry powder & Diskus $^{\circledR}$ & Dompè \\
\hline & Multidose dry powder & Diskus $^{\circledR}$ & Lusofarmaco (Milan, Italy) \\
\hline & Pressurized suspension & MDI & Lusofarmaco \\
\hline & Pressurized suspension & MDI & GlaxoSmithKline \\
\hline & Multidose dry powder & Diskus ${ }^{\circledR}$ & GlaxoSmithKline \\
\hline \multirow[t]{12}{*}{ Formoterol fumarate } & Multidose dry powder & Pulvina ${ }^{\circledR}$ & Chiesi (Parma, Italy) \\
\hline & Pressurized solution & MDI & Chiesi \\
\hline & Pressurized solution & MDI & Biofutura (Milan, Italy) \\
\hline & Single-dose dry powder & Aerolizer $^{\circledR}$ & Rottapharm (Monza, Italy) \\
\hline & Pressurized solution & MDI & Novartis (Basel, Switzerland) \\
\hline & Single-dose dry powder & Aerolizer $^{\circledR}$ & Novartis \\
\hline & Single-dose dry powder & Aerolizer $^{\circledast}$ & EuroGenerici (Milan, Italy) \\
\hline & Multidose dry powder & Novolizer $^{\circledR}$ & Meda Pharma (Solna, Sweden) \\
\hline & Single-dose dry powder & Aerolizer $^{\circledR}$ & S.F. group s.r.I (Pescara, Italy) \\
\hline & Single-dose dry powder & Aerolizer ${ }^{\circledR}$ & Italchimici (Pomezia, Italy) \\
\hline & Single-dose dry powder & Aerolizer $^{\circledR}$ & Genetic S.P.A. (Fisciano, Italy) \\
\hline & Pressurized solution & MDI & Caber (Rome, Italy) \\
\hline
\end{tabular}

(Continued) 
Table I (Continued)

\begin{tabular}{|c|c|c|c|}
\hline Drug & Formulation & Device & $\begin{array}{l}\text { Company (international headquarters } \\
\text { location) }\end{array}$ \\
\hline & Multidose dry powder & Pulvinal & Caber \\
\hline & Multidose dry powder & Turbohaler & AstraZeneca \\
\hline \multirow[t]{2}{*}{ Indacaterol } & Single-dose dry powder & Breezhaler $^{\circledR}$ & Chiesi \\
\hline & Single-dose dry powder & Breezhaler & Novartis \\
\hline Olodaterol & Soft mist inhaler & Respimat $^{\circledR}$ & Boehringer Ingelheim \\
\hline \multicolumn{4}{|l|}{ LAMA } \\
\hline \multirow[t]{2}{*}{ Tiotropium bromide } & Single-dose dry powder & Handihaler $^{\circledR}$ & Boehringer Ingelheim \\
\hline & Soft mist inhaler & Respimat & Boehringer Ingelheim \\
\hline \multirow[t]{2}{*}{ Aclidinium bromide } & Multidose dry powder & Genuair $^{\circledR}$ & Guidotti (Pisa, Italy) \\
\hline & Multidose dry powder & Genuair & AstraZeneca \\
\hline \multirow[t]{2}{*}{ Glycopyrronium bromide } & Single-dose dry powder & Breezhaler & Novartis \\
\hline & Single-dose dry powder & Breezhaler & Biofutura \\
\hline Umeclidinium bromide & Single-dose dry powder & ELLIPTA $^{\circledR}$ & GlaxoSmithKline \\
\hline \multicolumn{4}{|l|}{ SABA + SAMA } \\
\hline Fenoterol + ipratropium & Pressurized solution & Metered dose inhaler & Boehringer Ingelheim \\
\hline Salbutamol + ipratropium & Pressurized solution & Metered dose inhaler & Valeas (Milan, Italy) \\
\hline \multicolumn{4}{|l|}{ LABA + LAMA } \\
\hline \multirow{2}{*}{$\begin{array}{l}\text { Vilanterol + umeclidinium } \\
\text { bromide }\end{array}$} & Multidose dry powder & ELLIPTA & GlaxoSmithKline \\
\hline & Multidose dry powder & ELLIPTA & Menarini \\
\hline \multirow[t]{2}{*}{ Indacaterol + glycopyrronium bromide } & Single-dose dry powder & Breezhaler & Novartis \\
\hline & Single-dose dry powder & Breezhaler & Biofutura \\
\hline \multirow{2}{*}{ Formoterol + aclidinium bromide } & Multidose dry powder & Genuair & AstraZeneca \\
\hline & Multidose dry powder & Genuair & Guidotti \& Malesci \\
\hline Olodaterol + tiotropium bromide & Soft mist inhaler & Respimat & Boehringer Ingelheim \\
\hline \multicolumn{4}{|l|}{ LABA + ICS FDC } \\
\hline \multirow[t]{2}{*}{ Salbutamol + beclomethasone } & Pressurized suspension & Metered dose inhaler & Chiesi \\
\hline & Pressurized suspension jet & MDI Jet ${ }^{\circledR}$ & Chiesi \\
\hline \multirow[t]{4}{*}{ Salmeterol + fluticasone propionate } & Multidose dry powder & Diskus & Menarini \\
\hline & Dual blister dry powder & Elpenhaler $^{\circledR}$ & Caber \\
\hline & Multidose dry powder & Diskus & GlaxoSmithKline \\
\hline & Multidose dry powder & Forspiro $^{\circledR}$ & Sandoz \\
\hline \multirow[t]{4}{*}{ Formoterol fumarate + budesonide } & Multidose dry powder & Turbohaler & AstraZeneca \\
\hline & Multidose dry powder & Turbohaler & Sigma-Tau (Pomezia, Italy) \\
\hline & Multidose dry powder & Turbohaler & AstraZeneca \\
\hline & $\begin{array}{l}\text { Breath-actuated dry } \\
\text { powder }\end{array}$ & Spiromax $^{\circledR}$ & TEVA (Petah Tikva, Israel) \\
\hline \multirow[t]{2}{*}{ Vilanterol + fluticasone furoate } & Multidose dry powder & ELLIPTA & GlaxoSmithKline \\
\hline & Multidose dry powder & ELLIPTA & Menarini (Firenze, Italy) \\
\hline \multirow{3}{*}{$\begin{array}{l}\text { Formoterol fumarate }+ \\
\text { beclomethasone }\end{array}$} & Multidose dry powder & Nexthaler ${ }^{\circledR}$ & Dompè \\
\hline & Multidose dry powder & Nexthaler & Chiesi \\
\hline & Multidose dry powder & Nexthaler & Novartis \\
\hline
\end{tabular}

Notes: Non-bold text indicates the inhaled drugs that are licensed. Bold text indicates the inhaled drugs that will be launched soon.

Abbreviations: COPD, chronic obstructive pulmonary disease; FDC, fixed dose combination; ICS, inhaled corticosteroids; LAMA, long-acting antimuscarinic agents; LABA, long-acting $\beta_{2}$ agonists; MDI, metered-dose inhaler; SABA, short-acting $\beta_{2}$ agonists; SAMA, short-acting antimuscarinic antagonist.

prescribing possibilities. Therefore, switching drugs and/or inhalers could generate hundreds of potential treatment possibilities in daily clinical practice (Figure 1).

\section{Potential impact of switching inhaled drugs on costs}

No clear evidence from real-life research is available on the economic effects of switching drugs in COPD. However, when a switch of inhaler is envisaged, it is necessary to take account of both direct and indirect costs, such as those generated by potential worsening of the disease, impact on health-related quality of life, increased or reduced administration of other treatments, and use of health care resources. It is noteworthy that the cost of emergency treatment is greater than that of planned treatment. ${ }^{21}$

Measures to contain prescription costs are becoming increasingly common in many countries. The extensive 


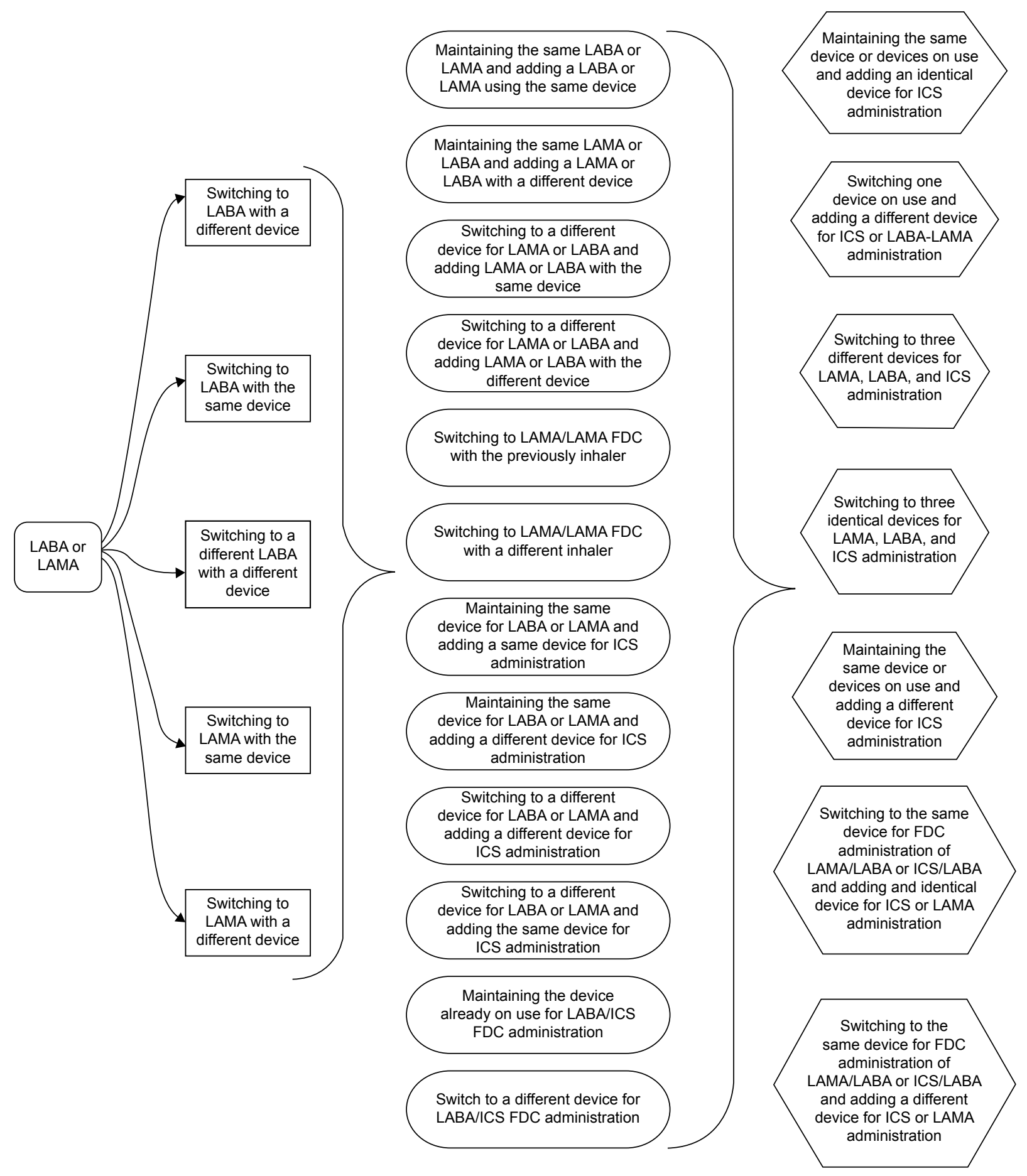

Figure I Potential switching possibilities in COPD inhaled treatment.

Abbreviations: COPD, chronic obstructive pulmonary disease; FDC, fixed dose combination; ICS, inhaled corticosteroids; LABA, long-acting $\beta_{2}$ agonists; LAMA, long-acting antimuscarinic agents.

use of generics may enable substantial savings to be made, theoretically at no detriment to patient care. Thus, switching from branded inhaled drugs to cheaper generic ones may reduce the costs of treating patients with COPD. ${ }^{22}$

The rules on substitution of branded drugs with generic drugs vary from country to country. ${ }^{22}$ In Germany and
Finland, for example, substitution with generic drugs is mandatory by law, while in the UK and the Netherlands, substitution is permitted if generic names are used on the prescription. In this case, continued use of a specific device is guaranteed by the phrase "medical necessity" on the prescription. Similarly, in Italy, pharmacists are free to switch 
patients with respiratory disease from a branded drug to a generic drug, unless the prescription states that the branded drug must not be switched. However, patients who refuse to substitute a branded product with a generic one must pay the difference in cost. The case of France deserves special mention, since there are no inhaled generics to replace branded products, although some pressurized metered-dose inhalers can be considered interchangeable. Since different devices require different techniques for use, switching could lead to poor inhalation procedures unless patients receive appropriate training. If appropriate training is not provided, patients may find it difficult to operate the device and may even stop using it. ${ }^{23}$ Research in patients with asthma has shown that appropriate instruction does not lead to differences in clinical outcomes, whereas a switch without previous consultation with the patient leads to poorer disease control. ${ }^{24}$ Optimization of current pharmacotherapy (eg, close monitoring of inhalation technique and medication adherence) is cost-effective, even in COPD, and should be considered before the patient is prescribed new therapy. ${ }^{25}$

\section{Potential impact of switching inhaled drugs on adherence to treatment}

Decreased adherence, whether intentional or unintentional, is a common outcome of switching. ${ }^{26}$ Unintentional nonadherence may occur because of poor handling technique, critical handling errors, an inability to recall consultations, and environmental constraints such as costs of or difficulty obtaining prescriptions. Patients may intentionally stop using an inhaler that they themselves did not choose. Patients do not have equal preferences for different inhalers, ${ }^{27}$ and in most cases, the higher the patient's satisfaction with the device, the greater the likelihood of good adherence and, therefore, more favorable outcomes. ${ }^{28}$ The efficiency of drug delivery can also be affected by patient preference, which, in turn, affects adherence to treatment and subsequent long-term control of the disease. DPIs, in particular, can vary markedly in design and method of operation, ${ }^{29}$ potentially leading to handling errors. ${ }^{30}$ When long-term users of branded inhaled drugs are dispensed generics delivered by a different inhaler, the potential change in taste/sensation could reduce their confidence in the efficacy of the generic drug and thus increase the risk of poor adherence and exacerbation. ${ }^{23}$

A structured questionnaire administered to physicians in France, Germany, and the UK showed that only 9\% of those interviewed thought that DPIs were interchangeable, while the remainder considered that these inhalers were not interchangeable. ${ }^{31}$ In addition, over $90 \%$ of the physicians thought that interchangeability of DPIs would have a negative impact on adherence and inhaler handling and the patient's willingness to use the inhaler if he/she was not involved in the choice of the device.

\section{Patient training: a key component}

A survey of health care professionals in the $\mathrm{UK}^{32}$ found that the vast majority were concerned about potential problems arising from prescriptions that do not specify the inhaler to be dispensed. In the survey by Price, ${ }^{31} 46 \%$ of the physicians interviewed were aware of patients who had received a different inhaler, the consequences of which included confusion, ineffective inhalation technique, and the need to reissue prescriptions. In a survey conducted in the primary and secondary care setting in three European countries, over one-half of all the respondents reported problems with the inhaler as one of the main reasons for switching inhaled therapy. Most physicians were opposed to substitution of one DPI for another if the pharmacist did not consult the patient and/or the physician. These findings indicate that health care professionals perceive inhalers as different and not interchangeable, with physicians opposed to substitution of one device by another without consultation with the patient and appropriate training. In addition, health care professionals believe that involving the patient in the choice of inhaler plays a key role in adherence. Interventions focused on inhalation technique and adherence to maintenance therapy in a community pharmacy setting showed that a planned intervention can improve drug therapy in patients with COPD and reduce hospitalization rates. ${ }^{33}$

COPD recommendations state that, regardless of the device prescribed, patients should receive appropriate training and undergo regular assessment of inhalation technique. ${ }^{1}$ However, the guidelines provide no information on how to provide training when a patient's branded drug is switched to a generic alternative, particularly if the patient is not aware of the switch. Consequently, patients do not receive counseling about the new medication and device from their health care provider, resulting in poor inhalation technique and loss of disease control. This finding is supported by evidence in asthma, ${ }^{23,24}$ while no specific trials have been developed for COPD. Nevertheless, given the disease course and treatment of both diseases, it seems reasonable to apply the findings for one disease to the other. Switching without the patient's consent may not result in cost savings, because of more frequent visits to the clinic for training and support and negative impacts on disease outcomes, resulting in higher short- and long-term health care costs. Although patient education and 
involvement in treatment decisions can improve adherence, ${ }^{29}$ the multidimensional nature of adherence means that no single intervention or strategy per se can enhance it. All those involved in the process (government authorities, patient organizations, scientific societies, stakeholders, and others) must cooperate to develop a combined action plan based on the individual needs of the patient. ${ }^{34}$

\section{Conclusion}

Switching drugs and inhalers warrants special attention in COPD management. Caution should be exercised before switching from one device to another, and both the physician and the patient should be involved in the decision to switch. When a generic inhaler replaces a branded inhaler, patients should be willing to use the new inhaler and receive adequate training. ${ }^{35}$ Importantly, the responsibility for such training needs to be clarified, because physicians may not be aware that a prescribed branded inhaler has been replaced with a generic one at the pharmacy. ${ }^{36}$

In conclusion, the pressure to reduce costs and ensure efficient allocation of limited health care resources means that any effort to improve adherence could generate cost savings resulting from decreased demand for health care services. In contrast, savings achieved in purchase costs could generate a greater net loss arising from increased consumption of health care resources to treat worsening of COPD symptoms and exacerbations.

\section{Acknowledgments}

Authors thank the Adherence 3C Project and ARMIA (Associazione Ricerca Malattie Immunologiche e Allergiche) for the scientific support in developing this paper.

\section{Disclosure}

Fulvio Braido has received congress lecture fees from Guidotti, Malesci, Menarini, GlaxoSmithKline, Chiesi, Novartis, AstraZeneca, Mundipharma, Zambon, Boheringer Ingheleim, Almirall, and Biofutura. Federico Lavorini has received speaker honoraria from AstraZeneca, Boehringer Ingelheim, Chiesi, GlaxoSmithKline, and TEVA. Francesco Blasi has received personal fees from Bayer, Novartis, Menarini, Guidotti, Almirall, AstraZeneca, Dompè, GlaxoSmithKline, and TEVA, and grants and personal fees from Pfizer, Chiesi, and Zambon. Ilaria Baiardini has received personal fees from Boehringer Ingelheim. Giorgio Walter Canonica has been a scientific consultant, researcher in clinical trials, and speaker at scientific meetings, seminars, and educational activities, for which he has been totally or partially supported by the following companies: Alk-Abelló, Allergopharma, Allergy Therapeutics, Lofarma, Stallergenes, Thermo Fisher, GlaxoSmithKline, Novartis, AstraZeneca, Mundipharma, Alimirall, and Chiesi. The authors report no other conflicts of interest in this work.

\section{References}

1. Global Strategy for the Diagnosis, Management and Prevention of COPD, Global Initiative for Chronic Obstructive Lung Disease (GOLD); 2014. Available from: http://www.goldcopd.org. Accessed November 16, 2014.

2. Brocklebank D, Ram F, Wright J, et al. Comparison of the effectiveness of inhaler devices in asthma and chronic obstructive airway disease; a systematic review of the literature. Health Technol Assess. 2001; 5(26):1-149.

3. Dolovich MB, Ahrens RC, Hess DR, et al. Device selection and outcomes of aerosol therapy: evidence-based guidelines: American College of Chest Physicians/American College of Asthma, Allergy, and Immunology. Chest. 2005;127(1):335-371.

4. Berlinski A. Assessing new technologies in aerosol medicine: strengths and limitations. Respir Care. 2015;60(6):833-849.

5. Laube BL, Janssens HM, De Jongh FH, et al. What the pulmonary specialist should know about the new inhalation therapies. Eur Respir J. 2011;37(6):1308-1331.

6. Crompton GK, Barnes PJ, Broeders M, et al. The need to improve inhalation technique in Europe: a report by the aerosol drug management improvement team. Respir Med. 2006;100(9):1479-1494.

7. Tashkin DP. Multiple dose regimens: impact on compliance. Chest 1995;107(5):176S-182S.

8. Tamura G, Ohta K. Adherence to treatment by patients with asthma or COPD: comparison between inhaled drugs and transdermal patch. Respir Med. 2007;101(9):1895-1902.

9. Vestbo J, Anderson JA, Calverley PM, et al. Adherence to inhaled therapy, mortality and hospital admission in COPD. Thorax. 2009; 64(11):939-943.

10. Carls GS, Roebuck MC, Brennan TA, Slezak JA, Matlin OS, Gibson TB. Impact of medication adherence on absenteeism and shortterm disability for five chronic diseases. J Occup Environ Med. 2012; 54(7):792-805.

11. Lavorini F, Magnan A, Dubus JC, et al. Effect of incorrect use of dry powder inhalers on management of patients with asthma and COPD. Respir Med. 2008;102(4):593-604.

12. Penning-van Beest F, van Herk-Sukel M, Gale R, Lammers JW, Herings R. Three-year dispensing patterns with long-acting inhaled drugs in COPD: a database analysis. Respir Med. 2011;105(2):259-266.

13. Rossi A, van der Molen T, del Olmo R, et al. INSTEAD: a randomised switch trial of indacaterol versus salmeterol/fluticasone in moderate COPD. Eur Respir J. 2014;44(6):1548-1555.

14. Hanada S, Wada S, Ohno T, Sawaguchi H, Muraki M, Tohda Y. Questionnaire on switching from the tiotropium HandiHaler to the Respimat inhaler in patients with chronic obstructive pulmonary disease: changes in handling and preferences immediately and several years after the switch. Int J Chron Obstruct Pulmon Dis. 2015;6(10):69-77.

15. Yu AP, Guérin A, Ponce de Leon D, et al. Therapy persistence and adherence in patients with chronic obstructive pulmonary disease: multiple versus single long-acting maintenance inhalers. J Med Econ. 2011;14(4):486-496.

16. Daley-Yates P, Parkins D. Establishing bioequivalence for inhaled drugs; weighing the evidence. Exp Opin Drug Deliv. 2011;8(11):1297-1308.

17. European Medicines Agency. Committee for Medicinal Products for Human Use (CHMP). Guideline on the requirements for clinical documentation for orally inhaled products (OIP) including the requirements for demonstration of therapeutic equivalence between two inhaled products for use in the treatment of asthma and chronic obstructive pulmonary disease. In: (CHMP) CfMPfHU, ed. London 2009. 
18. Guidance for industry: Guidance for the in vitro portion of bioequivalence requirements for metaproterenol sulfate and albuterol inhalation aerosols (metered dose inhalers). Center for Drug Evaluation and Research; US Department of Health and Human Services; Food and Drug Administration; 1989. Available at: http://www.fda.gov/downloads/Drugs/GuidanceComplianceRegulatoryInformation/Guidances/ ucm070242.pdf. Accessed August 3, 2015.

19. US Food and Drug Administration. US FDA. Drug-development approval process. Scientific and Regulatory Considerations for Bioequivalence (BE) of Dry Powder Inhalers (DPIs). Silver Spring, MD: US Food and Drug Administration; 2011.

20. La Banca Dati Farmaci [The drugs database]. Agenzia Italiana del Farmaco (AIFA). Available from: https://farmaci.agenziafarmaco.gov.it/. Accessed November 16, 2014. Italian.

21. GINA Report, Global Strategy for Asthma Management and Prevention; [updated December 2011]. Available from: http://www.ginasthma.org

22. Lavorini F, Ninane V, Haughney J, Bjermer L, Molimard M, Dekhuijzen RP. Switching from branded to generic inhaled medications: potential impact on asthma and COPD. Expert Opin Drug Deliv. 2013; 10(12):1597-1602.

23. Doyle S, Lloyd A, Williams A, et al. What happens to patients who have their asthma device switched without their consent? Prim Care Respir J. 2010;19(2):131-139.

24. Thomas M, Price D, Chrystyn H, et al. Inhaled corticosteroids for asthma: impact of practice level device switching on asthma control. BMC Pulm Med. 2009;9:1.

25. van Boven JF, Tommelein E, Boussery $\mathrm{K}$, et al. Improving inhaler adherence in patients with chronic obstructive pulmonary disease: a cost-effectiveness analysis. Respir Res. 2014;15:66.

26. Chrystyn H. Do patients show the same level of adherence with all dry powder inhalers? Int J Clin Pract Suppl. 2005;149:19-25.

27. Schulte M, Osseiran K, Betz R, et al. Handling of and preferences for available dry powder inhaler systems by patients with asthma and COPD. J Aerosol Med Pulm Drug Deliv. 2008;21(4):321-328.
28. Small M, Anderson P, Vickers A, Kay S, Fermer S. Importance of inhaler-device satisfaction in asthma treatment: real-world observations of physician-observed compliance and clinical/patient-reported outcomes. Adv Ther. 2011;28(3):202-212.

29. Azouz W, Chrystyn H. Clarifying the dilemmas about inhalation techniques for dry powder inhalers: integrating science with clinical practice. Prim Care Respir J. 2012;15(21):208-213.

30. Molimard M, Raherison C, Lignot S, Depont F, Abouelfath A, Moore N. Assessment of handling of inhaler devices in real life: an observational study in 3,811 patients in primary care. J Aerosol Med. 2003;16(3): 249-254.

31. Price D. Do healthcare professionals think that dry powder inhalers can be used interchangeably? Int J Clin Pract Suppl. 2005;149:26-29.

32. Buchanan A, Pinnock H, Barnes J, Hawksworth G, Weller T, Lynes D. Generic prescribing of breath actuated and dry powder inhalers in the UK. Prim Care Respir J. 2002;11(3):95.

33. Tommelein E, Mehuys E, Van Hees T, et al. Effectiveness of pharmaceutical care for patients with chronic obstructive pulmonary disease (PHARMACOP): a randomized controlled trial. Br J Clin Pharmacol. 2014;77(5):756-766.

34. Braido F, Baiardini I, Blasi F, Pawankar R, Canonica GW. Adherence to asthma treatments: 'we know, we intend, we advocate'. Curr Opin Allergy Clin Immunol. 2015;15(1):49-55.

35. Lavorini F, Braido F, Baiardini I, Blasi F, Canonica GW; SIAACSIMER. Asthma and COPD: interchangeable use of inhalers. A document of Italian Society of Allergy, Asthma and Clinical Immmunology (SIAAIC) \& Italian Society of Respiratory Medicine (SIMeR). Pulm Pharmacol Ther. Epub 2015 Jul 22.

36. Williams A, Chrystyn H. Survey of pharmacists' attitude towards interchangeable use of dry powder inhaler. Pharm World Sci. 2007;29(3): 221-227.
International Journal of COPD

\section{Publish your work in this journal}

The International Journal of COPD is an international, peer-reviewed journal of therapeutics and pharmacology focusing on concise rapid reporting of clinical studies and reviews in COPD. Special focus is given to the pathophysiological processes underlying the disease, intervention programs, patient focused education, and self management protocols.

\section{Dovepress}

This journal is indexed on PubMed Central, MedLine and CAS. The manuscript management system is completely online and includes a very quick and fair peer-review system, which is all easy to use. Visit http://www.dovepress.com/testimonials.php to read real quotes from published authors. 